\title{
Research on Zhanjiang-ASEAN Cruise Tourism Product Development Based on Shift-Share Analysis
}

\author{
Pang Lianrong ${ }^{1}$, Li Rui ${ }^{2}$ \\ ${ }^{1}$ Department of Business Management, Lingnan Normal University, Zhanjiang, China \\ ${ }^{2}$ Department of Life Sciences, Lingnan Normal University, Zhanjiang, China
}

Email address:

806834317@qq.com (Pang Lianrong), lnsylirui@qq.com (Li Rui)

\section{To cite this article:}

Pang Lianrong, Li Rui. Research on Zhanjiang-ASEAN Cruise Tourism Product Development Based on Shift-Share Analysis. Journal of Business and Economic Development. Vol. 4, No. 2, 2019, pp. 38-43. doi: 10.11648/j.jbed.20190402.11

Received: April 10, 2019; Accepted: May 23, 2019; Published: June 11, 2019

\begin{abstract}
At present, the development of cruise tourism products with the theme of "Maritime Silk Road" has received extensive attention. As the originating port of the ancient Maritime Silk Road, Zhanjiang has her unique advantage in carrying out the "Maritime Silk Road" cruise tourism. Based on Shift-Shareanalysis, this article analyses the cruise tourism in Zhanjiang by taking the ticket, tour, entertainment, shopping and other consumption activities as the dimensions. It believes that the overall development of Zhanjiang cruise tourism is good. The development potential of tourism and shopping in Zhanjiang is great, which has certain competitiveness in the whole country, though the growth rate of ticket and entertainment is slow and the competitiveness is weak at present. The main reason is that Zhanjiang cruise tourism infrastructure is underdeveloped, talents are lacking, products are not rich, and the lines are insufficient. This article indicates that traditional cruise tourism period with the ticket as the main source of income has passed, the current development of cruise tourism has entered the leisure and vacation period. Therefore, this article proposes investing funds to improve the construction of cruise tourist infrastructure, strengthening the construction of talent team engaged in cruise tourism, developing products to create "cruise +" diversified cruise tourism products, designing distinctive themes route to enhance the competitiveness of Zhanjiang cruise tourism.
\end{abstract}

Keywords: Cruise Tourism, Product Development, Shift-Share, Zhanjiang-ASEAN

\section{Introduction}

Cruise tourism is a high-end tourism activity, whichtaking the large luxury cruise ship as the carrier, take the sea cruise as the main form, take the boat activities and the shore tour as the main content. As a high-end tourism product with fast growth and great development potential in the international tourism market, cruise tourism has maintained an annual growth rate of $8 \%$ to $9 \%$ in recent years, far exceeding the overall growth rate of international tourism [1]. Therefore, cruise tourism is also regarded as "the gold industry floating on the golden waterway" [2]. Coastal port cities have also adjusted the industrial structure to promote the development of the cruise tourism industry [3]. Since the National Development and Reform Commission, the Ministry of Foreign Affairs, and the Ministry of Commerce jointly issued the "Vision and Action for Promoting the Construction of the Silk Road Economic Belt and the 21 st Century Maritime Silk Road," cruise tourism has become the mainstay of international boutique tourism routes and tourism products. It has also become an effective way for China-ASEAN tourism cooperation $[4,5]$. As a strategic pillar city in the Beibu Gulf, Zhanjiang has unique geographical advantages and political advantages in developing cruise tourism, especially under the promotion of China's "One Belt, One Road" propose. It is imperative to construct a Zhanjiang-ASEAN cruise tourism channel. However, the current research on cruise tourism is mainly reflected in macro aspects such as industrial development, competitiveness improvement, system construction, port structure, etc., and research on markets and products is less [6-8]. Therefore, this paper takes the main consumption components of cruise tourism as the basic dimension of ticket, tour, entertainment and shopping by the Shift-Share analysis method, combined with the statistical data of nearly ten years, to evaluate the development of Zhanjiang cruise tourism from the vertical and horizontal aspects. The situation 
provides suggestions for optimizing the development of Zhanjiang cruise tourism under the background of "Belt and Road", and discusses the development of Zhanjiang-ASEAN cruise tourism products from the aspects of fund guarantee, talent recruiting and training, product design and route planning.

\section{Methodology}

\subsection{Fundamental}

Shift-Share Method (SSM) is an analytical method of regional economics, based on the average annual growth rate of a certain industry in a certain period of the country [9]. The calculation of the development effect that the growth rate may achieve in an area is based on this through comparing the development effect of this calculation with the statistically actual development results of the region and analysing the shift of the industry structure in the region from the national average [10], so as to evaluate the benefits of this industry structure in the region.

\subsection{Mathematical Model}

The SSM analysis method can be applied to evaluate the tourism structure. According to this method, the growth of tourism economy in a certain region is related to three factors: the national factor of tourism economic growth, the industrial structure factor of tourism economic growth and the regional factors (also called competitive factors) in growth of tourism economy [11].

Let $C_{0}$ be the national tourism annual income; $C_{t}$ be the national tourism $t$ year income; according to certain rules, the tourism industry is divided into $n$ departments, and $C_{i 0}, C_{i t}$ respectively represent the country's tourism industry sector in the base year and the income scale of the whole year; let $Y_{0}$ be the total economic amount of the base year of a certain area, and $Y_{t}$ be the final period. $Y_{i 0}$ and $Y_{i t}$ respectively represent the economic aggregates of the base year and the end year of the $i$-th tourism industry sector in a certain region. From this, the rate of change $R_{i}$ and $r_{i}$ of the economic aggregate of the $i$-th industrial sector in the country and the region can be calculated. $G_{i}$ represents the economic growth of the tourism sector in the region after $t$ years, and the total economic growth of regional tourism $\mathrm{G}$ can be expressed as:

$$
G=N+P+D=\sum_{i=1}^{n} N_{i}+\sum_{i=1}^{n} P_{i}+\sum_{i=1}^{n} D_{i}
$$

Where $N_{i}$ is the share component, $\mathrm{Ni}=\mathrm{Y}^{\prime} \times \mathrm{R}_{\mathrm{i}}$; is the structural shift component, $\mathrm{Pi}=\left(\mathrm{Y}_{\mathrm{i} 0}-\mathrm{Y}^{\prime}{ }_{\mathrm{i}}\right) \times \mathrm{R}_{\mathrm{i}} ; D$ is the competitive shift component, $\mathrm{Di}=\mathrm{Y}_{\mathrm{i} 0} \times\left(\mathrm{r}_{\mathrm{i}}-\mathrm{R}_{\mathrm{i}}\right)$.

Let the relative growth rate of a certain region relative to the country be $L$, the structural effect index be $W$, and the regional competition effect index be $U$, then:

$$
\mathrm{L}=\frac{\mathrm{Y}_{\mathrm{t}}}{\mathrm{Y}_{0}} \div \frac{\mathrm{C}_{\mathrm{t}}}{\mathrm{C}_{0}}=\mathrm{W} \times \mathrm{U}
$$

$$
\begin{array}{r}
\mathrm{W}=\left(\frac{\sum_{\mathrm{i}=1}^{\mathrm{n}} \mathrm{k}_{\mathrm{i} 0} \times \mathrm{C}_{\mathrm{it}}}{\sum_{\mathrm{i}=1}^{\mathrm{n}} \mathrm{k}_{\mathrm{i} 0} \times \mathrm{C}_{\mathrm{i} 0}}\right) \div\left(\frac{\sum_{\mathrm{i}=1}^{\mathrm{n}} \mathrm{C}_{\mathrm{it}}}{\sum_{\mathrm{i}=1}^{\mathrm{n}} \mathrm{C}_{\mathrm{i} 0}}\right) \\
\mathrm{U}=\sum_{\mathrm{i}=1}^{\mathrm{n}} \mathrm{K}_{\mathrm{it}} \times \mathrm{C}_{\mathrm{it}} / \sum_{\mathrm{i}=1}^{\mathrm{n}} \mathrm{K}_{\mathrm{i} 0} \times \mathrm{C}_{\mathrm{it}}
\end{array}
$$

In (3) and (4), $k_{i 0}$ and $K_{i t}$ are the proportion of the $i$-th industrial sector in the base year and the end year, respectively, in the corresponding departments of the country.

If the value of $\mathrm{G}$ is large, $\mathrm{L}>1$, indicating that the tourism economy in the region is growing faster than the national level, and vice versa; if the value of $\mathrm{P}$ is large, $\mathrm{W}>1$, indicating that the proportion of the fast-growing sector in the tourism economy is large, the industrial structure preferable; if the value of $\mathrm{D}$ is large, $\mathrm{U}>1$, indicating that the tourism departments of the region are more competitive [12].

\subsection{Data Sources}

The data in this paper is mainly divided into two parts. Among them, China Cruise Tourism revenue and composition data are from the China Industrial Information Network, China Tourism Statistics Yearbook, Ctrip, eLong and other online travel transactions. The data is compiled; the Zhanjiang cruise tourism income and its composition are compiled from the data of Zhanjiang Statistics Bureau and Zhanjiang Statistical Yearbook. The composition of cruise tourism income is mainly divided into four aspects: ticket, tour, entertainment and shopping. The statistics range from 2010 to 2018 .

\section{SSM Analysis of Zhanjiang Cruise Tourism Structure}

\subsection{Development of the National Cruise Tourism Industry}

Since the National Development and Reform Commission, the Ministry of Foreign Affairs, and the Ministry of Commerce jointly issued the "Vision and Action for Promoting the Construction of the Silk Road Economic Belt and the 21 st Century Maritime Silk Road," cruise tourism has become the mainstay of international boutique tourism routes [13-15]. Coastal provinces such as Guangdong, Guangxi, Hainan and Fujian are also actively exploring the tourism cooperation and development strategy of the "Maritime Silk Road" [16], regarding cruise tourism as the main form of "Maritime Silk Road Tourism" development [17]. At present, China has built large international cruise ports in Tianjin, Qingdao, Shanghai, Xiamen, Sanya and other places, and has already put them into operation. The reception volume of cruise ships is increasing day by day [18]. In 2017, China's cruise ships received 3.78 million passengers and inbound and outbound passengers, with a growth rate of $48 \%$. The revenue of the cruise market was 8.23 billion yuan. It is estimated that the revenue of China's cruise market will exceed 12 billion yuan in 2019, as shown in Table 1. 
Table 1. China Cruise Tourism Incomes and Its CompositionUnit: 100 million yuan.

\begin{tabular}{|c|c|c|c|c|c|c|c|c|c|}
\hline Time & 2010 & 2011 & 2012 & 2013 & 2014 & 2015 & 2016 & 2017 & 2018 \\
\hline Total revenue & 23.8 & 7.1 & 11.8 & 26.2 & 33.5 & 45.3 & 60.8 & 82.3 & 111.3 \\
\hline Ticket & 8.90 & 3.20 & 4.72 & 12.6 & 15.10 & 18.60 & 23.71 & 37.86 & 62.33 \\
\hline Tour & 5.76 & 1.42 & 1.77 & 3.14 & 6.70 & 9.97 & 16.42 & 17.28 & 25.60 \\
\hline Entertainment & 2.67 & 0.64 & 1.18 & 3.14 & 3.02 & 5.89 & 3.65 & 18.93 & 12.24 \\
\hline Shopping & 5.76 & 1.78 & 2.95 & 4.72 & 8.38 & 8.15 & 10.34 & 7.41 & 8.90 \\
\hline Others & 0.71 & 0.07 & 1.18 & 2.62 & 0.34 & 2.72 & 6.69 & 0.82 & 2.23 \\
\hline
\end{tabular}

Data source: According to the data of Zhiyan Consulting Report and China Tourism Statistics Yearbook.

\subsection{Development of Zhanjiang Cruise Tourism}

Compared with the whole country, the development of Zhanjiang cruise tourism is still in infancy, mainly based on the cruise terminal. Since the first time the Norwegian luxury cruise ship "Royal Star" berthed in Zhanjiang Port in 1984, Singapore's "Lion", Hong Kong Star Cruises "Libra Star" and "Aquarius Star" have also visited Zhan several times. The number of tourist receptions varies from 1000 to 3000 each time. However, due to the lack of a dedicated cruise terminal, the large-scale cruise ship visit to Zhanjiang can only temporarily stop at the dock of the operation area of Zhanjiang Port, which seriously affected the image of Zhanjiang as an excellent tourist city in China. Therefore, as early as 2011, "Guangdong Province Cruise Tourism Development Plan" clearly clarified the idea of Zhanjiang to build a cruise port and port of call. And in 2015, under the strategic requirements of the construction of the "Belt and Road" maritime cooperation strategic fulcrum city, "Guangdong Province Participating in the Construction of the 'Belt and Road'ImplementationPlan" and the Zhanjiang Municipal Government's Work Report further proposed that Zhanjiang should build a cruise port and develop a "New Silk Road" cruise route. In 2018, the Zhanjiang Municipal Government also proposed to build an international cruise port complex project with marine features integrating "commercial office, cultural entertainment, leisure tourism and ecological residence". At present, Zhanjiang cruise tourism revenue mainly comes from the "Red-billed Gull" cruise tourism project. The income of Zhanjiang cruise tourism since 2010 is shown in Table 2.

Table 2. Zhanjiang Cruise Tourism Incomes and Its CompositionUnit: 100 million yuan.

\begin{tabular}{|c|c|c|c|c|c|c|c|c|c|}
\hline Time & 2010 & 2011 & 2012 & 2013 & 2014 & 2015 & 2016 & 2017 & 2018 \\
\hline Total revenue & 0.6 & 0.9 & 1.3 & 1.6 & 2.2 & 2.6 & 3.4 & 3.9 & 4.6 \\
\hline Ticket & 0.48 & 0.66 & 0.92 & 1.09 & 1.41 & 1.56 & 1.70 & 1.95 & 2.35 \\
\hline Tour & 0.05 & 0.11 & 0.13 & 0.21 & 0.37 & 0.26 & 0.41 & 0.78 & 0.92 \\
\hline Shopping & 0.04 & 0.11 & 0.13 & 0.19 & 0.22 & 0.52 & 0.78 & 0.62 & 0.37 \\
\hline Others & 0.02 & 0.01 & 0.10 & 0.06 & 0.04 & 0.10 & 0.24 & 0.16 & 0.14 \\
\hline
\end{tabular}

Data source: According to the data of Zhanjiang Statistics Bureau and Zhanjiang Statistical Yearbook.

\subsection{SSM Analysis}

This paper takes the ticket, tour, entertainment and shopping as the main dimensions of cruise tourism income, taking 2010 as the base year and 2018 as the final year, the main income source of Zhanjiang cruise tourism to form
SSM analysis (as is shown in Table 3). And from SSM analysis we evaluate the structural benefits of Zhanjiang cruise tourism development and determine the merits of Zhanjiang cruise tourism structure and the strength of competitiveness.

Table 3. SSM Analysis of Zhanjiang Cruise Tourism IncomesUnit: 100 million yuan.

\begin{tabular}{|c|c|c|c|c|c|c|c|c|}
\hline Composition & $\mathrm{C}_{\mathrm{i} 0}$ & $\mathrm{C}_{\mathrm{it}}$ & $\mathbf{Y}_{\mathrm{i} 0}$ & $Y_{i t}$ & $\mathbf{N}_{\mathbf{i}}$ & $\mathbf{P}_{\mathrm{i}}$ & $\mathbf{D}_{\mathrm{i}}$ & $\mathbf{P D}_{\mathrm{i}}$ \\
\hline Ticket & 8.9 & 62.33 & 0.48 & 2.35 & 8.34 & 5.46 & -1.02 & 4.45 \\
\hline Tour & 5.76 & 25.60 & 0.05 & 0.92 & 1.03 & 0.85 & 0.68 & 1.53 \\
\hline Entertainment & 2.67 & 12.24 & 0.01 & 0.83 & 0.97 & 0.95 & -0.80 & 1.75 \\
\hline Shopping & 5.76 & 8.90 & 0.04 & 0.37 & 0.35 & 0.33 & 0.30 & 0.63 \\
\hline Others & 0.71 & 2.23 & 0.02 & 0.14 & 1.10 & 1.06 & 0.08 & 1.14 \\
\hline
\end{tabular}

Table 4. The Comprehensive Effect of Zhanjiang Cruise Tourism Development.

\begin{tabular}{|c|c|c|c|c|}
\hline Item & Structural Effect Index W & Competitive Effect Index U & Competitively Growth Index L & Economic Aggregate G \\
\hline Effect Value & 1.34 & 0.4 & 0.54 & 21.3 \\
\hline
\end{tabular}

Table 4. Continue.

\begin{tabular}{|c|c|c|c|c|}
\hline Item & Total Share Component N & Total structure Shift component P & Total competitiveness Shift component D & Total Shift component PD \\
\hline Effect Value & 11.8 & 8.65 & 0.85 & 9.5 \\
\hline
\end{tabular}


According to the analysis of the Shift-Share of Zhanjiang cruise tourism income from Table 3 , it can be seen that the ranks of Zhanjiang cruise tourism incomes are basically unchanged from the base year to the endyear:according to the order of ticket - tour-entertainment-shopping - other incomes, but the growth rate of entertainment and shopping consumption is clearly leading. From a national perspective, entertainment consumption has increased significantly, followed by tourist spending. This shows that people are paying more and more attention to the product design of cruise tour when choosing it. Through further analysis of the composition of each consumer, it can be found that the share component $\mathrm{Ni}$, the structural shift component $\mathrm{Pi}$ and the competitive shift component $\mathrm{Di}$ of the two major consumptions of tourism and shopping are all greater than 0 , indicating that the two aspects of Zhanjiang cruise tourism have good development momentum and development potential. Zhanjiang has a certain degree of competitiveness in the country. The share component $\mathrm{Ni}$ and the structural shift component $\mathrm{Pi}$ of the ticket and entertainment are greater than 0 , but the competitive component $\mathrm{Di}$ is less than 0 , indicating that although these two aspects have developed, the growth rate is slow and the competitiveness is not strong. It shows the momentum of recession.

From the overall comprehensive effect of Zhanjiang cruise tourism development in Table 4, it can be seen that between 2010 and 2018, the economic growth of Zhanjiang cruise tourism $\mathrm{G}=21.3$ billion yuan, the relative growth rate $\mathrm{L}=0.54<1$, indicating that the development of Zhanjiang cruise tourism is fast. However, Zhanjiang's growth rate is lower than the national average. The total shift component $\mathrm{P}=865$ million, the structural effect index $\mathrm{W}=1.34>1$, indicating that the contribution rate of Zhanjiang cruise tourism to the economy is not high, and the consumption structure needs further adjustment. In addition, Zhanjiang cruise tourism total competitiveness index $\mathrm{U}=0.4<1$, total competitiveness shift component $\mathrm{D}=0.85<100$ million, indicating that the overall competitiveness of Zhanjiang cruise tourism is poor.

\subsection{Summary}

First, Zhanjiang cruise tourism has a good momentum of development on the whole, but its growth rate is lower than the national average and its competitiveness is weak. This is mainly due to the fact that Zhanjiang's existing cruise tourist facilities are relatively backward and there is no dedicated cruise terminal. There is also no route from Zhanjiang to the port of origin. Therefore, it is necessary to invest funds to build the infrastructure of the cruise ship.

Secondly, the ticket is always the main income component of cruise tourism. However, under the current diversified consumption situation, the revenue-generating model based on ticket is bound to affect the competitive advantage of cruise tourism. Therefore, the development of cruise tourism should be diversified product development.

Thirdly, the proportion of tourism and shopping in cruise tourism revenue has increased year by year, indicating that consumers have greater demand for these two aspects. Therefore, we must focus on the competitive advantages of Zhanjiang Cruise Tourism from the design of products and the development of routes.

Fourthly, entertainment consumption is slower in the income of Zhanjiang cruise tourism, and it lacks competitiveness. It can enhance the competitiveness of Zhanjiang cruise tourism by enriching cruise entertainment projects and promoting cruise talent training.

Based on the above conclusions, the traditional cruise tourism period with the ticket as the main source of income has passed. The current development of cruise tourism has entered the stage of sea leisure vacation ${ }^{[12]}$. It is necessary to start from product development and optimize the cruise tourist consumption structure to enhance the competitiveness of tourism development.

\section{Zhanjiang-ASEAN Cruise Tourist Product Development Suggestions}

According to the competitiveness of Zhanjiang cruise consumption, combined with the background of the development of the Belt and Road, relying on the geographical advantages facing Southeast Asia, the Zhanjiang cruise tourist product development plan is determined from the aspects of capital, talents, products and routes.

\subsection{Investing Funds to Improve the Construction of Cruise Tourist Infrastructure}

The development speed of Zhanjiang cruise tourism is lower than the national average, which reason is the backward infrastructures. The construction of a series of infrastructures such as port construction, cruise construction, facility configuration, and operation management are inseparable from the investment of huge amounts of funds. At present, China does not have the ability to build cruise ships independently and does not have enough professional cruise management talents. If the infrastructure construction relies on the business alone, it will inevitably cause a lot of pressure. Therefore, on the one hand, the state should introduce relevant policies to support the development of new formats for cruise tourism, such as setting up special funds for cruise tourism development, improving subsidy policies, and accelerating the construction of ports, terminals, and onshore infrastructure. On the other hand, it is necessary to broaden the funding channels for cruise tourism and actively absorb various forms of funds such as foreign investment, bank financing, and government funding to invest in infrastructure construction.

\subsection{Training Talents and Strengthening the Construction of Talent Team Engaged in Cruise Tourism}

It can be seen from the shift share analysis that the 
development of Zhanjiang cruise tourism is faster, but the competitiveness is weaker. The shortage of professional talents is a big constraint. The training of domestic cruise tourism professionals, mostly mixed with hotels, tour guides, etc., lacks professionalism and pertinence. In combination with the special nature of the "Maritime Silk Road" cruise route, in terms of personnel training, we must actively learn from overseas management experience and improve the professionalism of talents on the one hand; on the other hand, we must broaden talents' knowledge of tourism in literature, art books, and history, in order to enriching cruise tourism activities.

\subsection{Developing Products to Create "Cruise +" Diversified Cruise Tourism Products}

With the advent of the mass leisure era, the needs of tourists are also diversified. According to the consumption structure competitiveness and resource endowment of Zhanjiang cruise tourism, we can focus on creating a diversified product of cruise + cultural experience, cruise + leisure health, cruise + food shopping, cruise + parent-child education.

\subsubsection{Cruise + Cultural Experience}

"Re-taking the ancient Maritime Silk Road" is the core of the cultural experience. First, we must carry out the "Looking for the Footprint of Maritime Silk Road" activities, and connect the historical and cultural cities of Maritime Silk Road, famous tombs, celebrities, temples, and underwater heritage to let visitors experience and pursue the spirit of the ancient Maritime Silk Road. Secondly, we must create a Southeast Asian culture and experience products, and combine the folk art of Zhanjiang, the folk customs of the south-eastern peninsula of Beihai, Qinzhou and Fangchenggang, the religious culture of Southeast Asian countries, the Songkran Festival, the Nanwang Dance, and the dance of the people and the folk songs, so that tourists can enjoy the exotic customs.

\subsubsection{Cruise + Leisure Health}

Leisure health is the main product of modern cruise tourism. On the one hand, with the beautiful coastal scenery, unique geological landscape and rich island culture of Zhanjiang, Beihai, Vietnam, Thailand, Malaysia, you can plan a series of activities such as coastal leisure, seabed adventure, leisure fishing and water sports. On the other hand, it can rely on the land service base to carry out business meetings, forest health, and rural leisure projects.

\subsubsection{Cruise + Food and Shopping}

For Chinese tourists visiting Southeast Asian countries, food and shopping has always been the main consumer content. The "Maritime Silk Road" has a wide variety of foods along the line. Fruits, seafood and snacks are numerous, and every time you go, you can have a big meal for visitors. In terms of shopping, Vietnam, Thailand, Singapore and other countries are rich in products, especially medicines, health products, jewellery and cosmetics. They are of various types, good quality and low price, and have been favored by tourists.

\subsubsection{Cruise + Parent-Children Education}

High-quality parent-children education and tourism products have been in short supply. For example, the moviethemed parent-children education tour launched by Royal Caribbean International Cruises, Disney's flagship Disney Sea Cruise Line has always been popular with tourists. The tourism resources on the "Maritime Silk Road" are very rich, involving natural geography, religious culture, folk customs, architectural food, exotic customs, a variety of material (intangible) cultural heritage and a number of patriotic education bases, plus cruises. The leisure characteristics of tourism are very suitable for the development of family parent-children education.

\subsection{Designing Route, Developing a Cruise Route with Distinctive Themes}

The design of tourist routes should follow the above four tourism product direction. Although each tourism route is based on the "Maritime Silk Road", the target group and the focus of the tour are different.

\subsubsection{Cruise + Cultural Experience: Long-term, In-depth Experience Travel (50-80 Days)}

The target tourists are positioned as high-end consumer groups, mainly including elites from culture, education, medical care, business, etc. And the launching of smart tourism routes that use modern information technology be combined with the re-taking the "Maritime Silk Road". The route of Zhanjiang's "Maritime Silk Road" cultural experience tourism products includes Donghai Island Weizhou Island - Leizhou - Xuwen - Hepu - Beihai Fangchenggang - Halong Bay - Hanoi - Haiphong - Hue - Ho Chi Minh City - Phnom Penh - Pattaya - Bangkok - Phuket Penang - Kuala Lumpur - Malacca - Singapore - Bali Brunei - Philippines - Hainan -Zhanjiang.

\subsubsection{Cruise + Leisure Health: Medium and Long-term, Business and Leisure Travel (20-30 Days)}

This route focuses on top business people and company conference teams, highlighting the characteristics of business, comfort and leisure in the arrangement of the tour. The route plan is: Zhanjiang Nansan Island - Beihai YintanFangchenggang-ShiwanDashan Forest - Vietnam Halong Bay - Thailand Phuket - Thailand Pattaya - Singapore - Malacca Genting Highlands - Bali - Nansha Islands - Haikou Zhanjiang.

\subsubsection{Cruise + Food and Shopping: Short-term, Leisure Experience Tour (10-15 Days)}

The target group is positioned as urban high-income whitecollar workers, mainly in the female market, and the slowpaced line arrangement. The route plan is: Zhanjiang Weizhou Island - Hepu - Beihai - Hanoi - Bangkok Singapore - Malacca - Kuala Lumpur - Haikou - Zhanjiang. 


\subsubsection{Cruise + Parent-Children Education: Short-term, Family Leisure Tour (10-15 Days)}

The goal is to target high-income families in the form of family outings, highlighting science and education, and leisure. The route plan is: Leizhou - Xuwen - Hepu - Hanoi NhaTrang - Angkor Wat - Ho Chi Minh City - Phnom Penh Bangkok - Singapore - Malacca - Kuala Lumpur - Xisha Islands - Haikou - Zhanjiang.

\section{Conclusion}

With the advent of the era of mass leisure tourism, cruise tourism has begun to emerge in the market. Especially under the influence of the "One Belt, One Road", Zhanjiang cruise tourism has great development prospects. In the development of Zhanjiang-ASEAN cruise tourist products, we must closely follow the theme of the Maritime Silk Road, highlighting the heterogeneity of products, developing diversified products, focusing on the competitive advantages of products. In the next step, we should customize a more perfect travel route according to the needs of tourists, which should emphasize the experience, leisure and education in its products.

\section{Acknowledgements}

This article was supported by South China Sea Silk Road Collaborative Innovation Center funded projects.

\section{References}

[1] Zhou Jianbiao. Developing the cultural tourism of the Maritime Silk Road and promoting the construction of the core area of the Maritime Silk Road [J]. Journal of Huanghe University of Science and Technology. 2016 (9): 67-73.

[2] Sun Xiaodong, Feng Xuegang. China Cruise Tourism Industry: Research Status and Prospects [J]. Tourism Journal, 2012, 27(2): 101-112.

[3] Shen Suwen. The latest trend of the global luxury cruise group [J]. China Ship Inspection. 2016 (9): 88-91.

[4] Asic A, Djelovic D. Ports Dubrovnik and Bar Cooperation Opportunities for Development of Sustainable Cruise Tourism [M]. Sustainable Development of Sea-Corridors and Coastal Waters. Springer International Publishing, 2015: 239-249.

[5] MilušeTichavska, Beatriz Tovar. Port-city exhaust emission model: An application to cruise and ferry operations in Las Palmas Port [J]. Transportation Research Part A: Policy and Practice, 2015(78): 347-360.

[6] Chen J M, Lijesen M G, Nijkamp P. Interpretation of cruise industry in a two-sided market context: An exploration on Japan [J]. Maritime Policy \& Management, 2017(2): 1-12.

[7] Jeong Cheol Yang. A comparative evaluation of maincruis eports in Korea, China and Japan in Northeast Asia [J] A comparative evaluation of main cruise ports in Korea, China and Japan in Northeast Asia, 2016 (6): 63-70.

[8] Ignacio Ruiz-Guerra, Valentín Molina-Moreno, Francisco J. Cortés-García, Pedro Núñez-Cacho. Prediction of the impact on air quality of the cities receiving cruise tourism: the case of the Port of Barcelona [J]. Heliyon. 2019(3): 1-26.

[9] Zhao Fan. The quantitative measure on inter-regional industry transfer and pollution transfer based on the idea of shift share analysis [M]. South-Central University. 2018.

[10] Zhang Xiang. Evaluation of Tourism Structure Benefit Based on Shift-Share Analysis-Taking Wuyishan City as an Example [J]. Journal of Xiangfan University, 2010(11).

[11] Wang Yingtao. Shift-share analysis and optimization of Henan international tourism industry structure $[\mathrm{J}]$. Areal Research and Development, 2018 (8): 110-113.

[12] Market Economics. New Zealand Cruise Industry Study [R]. 2010.

[13] QI Yan. Cruise Ship Tourism [J]. Journal Leisure Studies. 2019(38): 288-290.

[14] Deng Yingying. Effective Path of Maritime Silk Road Construction in the 21st Century: China-ASEAN Tourism Cooperation [J]. Around Southeast Asia, 2015(10): 15-21.

[15] Wang Wei, Zhang Yuxiu. Discussion on Accelerating the Development of New Business Format of Hainan Cruise Tourism [J]. The Journal of South China Sea Studies, 2016(9): $113-118$.

[16] Zhou Yilong. Tourism Cooperation and Development Strategy of Qiongyue "Maritime Silk Road" [J]. Nan Fang Lun Kan. 2015(8): 11-24.

[17] Chen Yuhe, Yin Ming. Discussion on the development of China's cruise industry under the "Belt and Road Initiative" $[\mathrm{J}]$. Practice in Foreign Economic Relations and Trade, 2018(12): 45-48.

[18] Mei Junqing, Ye Xinliang. Problems and Countermeasures of China's Cruise Tourism Industry from an International Perspective [J]. Shipping Management, 2018(1): 31-34. 